EDE ECONOMIAE
EAGRONEGÓCIO

ISSN impresso: 1679-1614

ISSN online: $2526-5539$

Vol. 17 | N. 1 | 2019

1 Universidade Federal de São Carlos, Sorocaba, São Paulo, Brasil.

* danilo@ufscar.br

\section{AVALIAÇÃO DA SITUAÇÃO NUTRICIONAL NO BRASIL: EFEITOS REGIONAIS E DA RENDA}

\section{RESUMO}

Este artigo examina como a desnutrição afeta os brasileiros de diferentes níveis de renda, que residem em cada uma das 26 capitais estaduais do país e no Distrito Federal, utilizando dados da Pesquisa de Orçamentos Familiares (POF) 2008-2009, realizada pelo Instituto Brasileiro de Geografia e Estatística (IBGE). Foram utilizados métodos de estatística descritiva e inferência estatística (estimação da curva de Engel) para avaliar as dietas consumidas pelos indivíduos dos diferentes grupos. Os resultados mostram que as dietas variam muito de acordo com a região e com o estrato de renda no qual o indivíduo se situa. A deficiência de calorias encontra-se disseminada pelo país, afetando especialmente aqueles de menor renda (mesmo os que residem nas cidades mais ricas), enquanto a maioria das pessoas consome mais do que o necessário em termos de proteína. Como as diferenças no acesso alimentar ocorrem principalmente, embora não exclusivamente, devido à distribuição de renda, políticas que visem a transferir renda ou reduzir o preço dos alimentos para os indivíduos mais pobres ajudariam a combater a desnutrição no país.

Palavras-chave: Desnutrição; Dietas Regionais; Distribuição de Renda.

\begin{abstract}
This paper examines how malnutrition affects Brazilians from different income levels, living in each of the 26 state capitals of Brazil plus the Federal District, using Household survey data of 2008-2009 collected by Brazilian Institute of Geography and Statistics (IBGE). Descriptive statistics plus inference methods (Engel's curve estimation) were used to assess food diets consumed by individuals from different groups. The results show that diets are quite different according to region and income level. Calories deficiency is widespread in the country, affecting especially low-income individuals (even those who live in richer cities), while most people eat more than enough of protein. As differences in access to food are mainly, though not exclusively, due to income distribution, policies aiming to either transfer income or reduce food prices to the poor would help fighting malnutrition in Brazil.
\end{abstract}

Keywords: Malnutrition; Regional Diets; Income Distribution.

JEL Code: D12. 


\section{INTRODUÇÃO}

Os esforços mundiais no combate à fome e à desnutrição vêm obtendo resultados expressivos desde o início deste século, sendo que os níveis da fome no mundo decresceram 27\% entre 2000 e 2017 (VON GREBMER et al., 2017). Entretanto, os anos mais recentes apontam para um retrocesso, com o número de pessoas desnutridas aumentando de 804 milhões para 821 milhões entre 2016 e 2017 (FAO, IFAD, UNICEF, WFP and WHO, 2018), o que mostra que ainda há muito a ser feito para que a meta global de erradicar a fome em 2030 seja atingida (VON GREBMER et al., 2017).

Embora o Brasil esteja entre os países em que a gravidade do problema da fome é considerada baixa (VON GREBMER et al., 2017), a questão ainda merece atenção. Segundo dados da PNAD (IBGE, 2010a; IBGE, 2014), 65,5 milhões de pessoas que residiam no país estavam sob algum grau de insegurança alimentar em 2009, número este que diminuiu para pouco mais de 51 milhões de pessoas em 2013. Ademais, tanto em 2009 quanto em 2013, cerca de $60 \%$ das pessoas que viviam em condições de carência alimentar residiam em áreas urbanas e tinham rendimento de até um salário mínimo per capita. Esses números contrastam com a crescente disponibilidade e estabilidade da oferta de alimentos no país (AGUIAR COSTA, 2017), o que sugere que fatores econômicos têm restringido o acesso aos alimentos por parte da população brasileira.

No tocante à análise da fome e da desnutrição, dois conceitos fundamentais têm sido muito utilizados: "situação alimentar" e "situação nutricional". O primeiro se refere à quantidade de alimentos a que os indivíduos de uma população têm acesso, enquanto o segundo corresponde à quantidade ingerida de nutrientes (WEINGÄRTNER, 2014). Embora sejam, rigorosamente, conceitos distintos, em muitos contextos eles são usados conjuntamente, ou são tratados indistintamente, como se faz neste artigo, por serem, na prática, muito semelhantes ${ }^{1}$. Na verdade, a situação nutricional de uma população é fortemente influenciada por sua situação alimentar, já que as pessoas precisam ter acesso ao alimento para poderem se nutrir, de forma que os principais determinantes da situação alimentar também o são da situação nutricional.

A situação alimentar de um país é afetada por diversos fatores, como se verá no próximo item. Mas num país de extensão continental como o Brasil, com grande diversidade espacial e enorme desigualdade na distribuição de renda, merecem especial atenção os fatores "renda" e "região geográfica". Considerando os dois artigos mais recentes que se mostram relevantes para a análise desse fatores, destaca-se, em relação à renda, o estudo conduzido por Hoffmann (2014), que identificou, por meio dos dados da Pesquisa Nacional por Amostra de Domicílios (PNAD) de 2013, a renda domiciliar per capita e a redução da desigualdade na distribuição da renda entre os

1 Mesmo considerando que se tratam de dois conceitos distintos e que a questão da segurança nutricional vai além da segurança alimentar, Weingärtner (2014) e outros autores, tais como Gross et al. (2000) e Frison et al. (2011), utilizam o termo conjunto "segurança alimentar e nutricional" (Food and Nutrition Security).

Revista de Economia e Agronegócio - REA | V. 17 | N. 1 | 2019 | pág. 9 
principais determinantes da melhoria da situação alimentar do país ocorrida até então, tendo esse autor, porém, conduzido uma análise mais agregada. Quanto à dimensão regional, merece destaque a pesquisa de Costa et al. (2014) que, por meio de um modelo logit aplicado a dados da Pesquisa de Orçamentos Familiares (POF) do IBGE de 2008-2009 e segmentando o Brasil por regiões, verificaram não haver diferenças significativas nas chances de os indivíduos domiciliados no Nordeste, Norte e Sudeste do Brasil ingerirem quantidade de calorias não inferior às suas necessidades, sendo essas chances menores nos domicílios localizados no Centro-Oeste e maiores nos da região Sul. Outras pesquisas relevantes também foram desenvolvidas, tais como por Coelho (2006), Pereda e Alves (2012) e Rodrigues et al. (2012), que estimaram sistemas de demanda para grupos de alimentos ou para nutrientes obtendo elasticidades preço e renda para essas variáveis. Embora esses artigos tenham apresentado alguns resultados discriminados por estado/região metropolitana, estimaram as funções para o Brasil como todo, utilizaram dados da POF 2002-2003 (ou anterior) e não investigaram o grau de atendimento das necessidades nutricionais da população.

Mesmo que os artigos supracitados tenham contribuído consideravelmente para a compreensão da questão da desnutrição, contribuição adicional poderia advir de análises que considerassem os dados desagregados em nível de estados da federação e examinassem o grau de atendimento nutricional das famílias em cada unidade federativa, utilizando como fonte de dados a POF mais recente disponível. Ea é justamente a proposta deste trabalho, que tem como objetivo examinar detalhadamente a situação alimentar dos residentes das capitais dos estados brasileiros e do Distrito Federal, classificados por estratos de renda, a partir de dados da POF 20082009, avaliando-se o tipo de produto consumido e a ingestão de calorias e proteínas. Com isso, pretende-se identificar os grupos da população mais sujeitos à desnutrição, saber que tipo de dieta eles consomem e em que locais residem, gerando assim informações importantes para embasar o planejamento de políticas públicas de combate à fome e à desnutrição.

O texto se organiza em mais quatro itens, além desta introdução. O segundo item apresenta brevemente o conceito de segurança alimentar e seus principais determinantes, visando a situar os fatores "renda" e "região", explorados neste artigo, no contexto da segurança alimentar. O terceiro apresenta os procedimentos metodológicos, o quarto demonstra e discute os resultados empíricos e o quinto traz as conclusões da pesquisa.

\section{SEGURANÇA ALIMENTAR: DIMENSÕES E DETERMINANTES}

O conceito utilizado para avaliar a situação alimentar é o de "segurança alimentar". De maneira simplificada, existe segurança alimentar quando todos os indivíduos de uma sociedade têm acesso à quantidade de alimentos que iguala ou supera suas necessidades nutricionais; caso contrário, se diz que há insegurança alimentar. De maneira mais formal, define-se segurança alimentar como a situação em que "todas as pessoas, em todos os momentos, têm acesso físico, social e econômico a alimentos 
suficientes, seguros e nutritivos para satisfazer as suas necessidades dietéticas e preferências alimentares para uma vida ativa e saudável" (WORLD FOOD SUMMIT, 1996). Esse conceito envolve quatro dimensões: disponibilidade, acesso, utilização e estabilidade alimentar (FAO, 2006; FAO, 2014).

A dimensão correspondente à disponibilidade refere-se à quantidade, à qualidade e à diversidade da oferta de alimentos e é determinada, principalmente, pela produção e pelo comércio, que contribui para o aumento dessa disponibilidade, trazendo alimentos de outros locais, ou para sua redução, por meio da exportação. Contudo, a simples existência de alimentos não garante que estes estarão acessíveis para o consumo de todos os indivíduos (SEN, 1981; WORLD BANK, 1986; MAXWELL; FRANKENBERG, 1992), o que aponta para a segunda dimensão: o acesso.

$\mathrm{O}$ acesso refere-se à capacidade econômica e física de se obter os alimentos disponíveis de forma socialmente aceita, como a troca, a compra, a produção ou a caça. Naturalmente, a disponibilidade influencia o acesso, pois, na ausência do alimento, ele não estará disponível a ninguém. Todavia, há também variáveis econômicas que determinam diretamente o acesso aos alimentos, tais como a renda (em relação aos preços) (MAXWELL; FRANKENBERG, 1992; VON GREBMER et al., 2017) e o sistema de distribuição (FAO, 2006; FAO, 2014; LOCKE; HENLEY, 2014).

A renda e sua distribuição entre os indivíduos, regiões e países têm importância direta e indireta sobre o acesso alimentar (MUSGROVE, 1987; MAXWELL; FRANKENBERG, 1992; AGUIAR, 1998). Diretamente, a renda e sua distribuição, juntamente com o preço dos alimentos, afetam o acesso alimentar quanto à determinação da quantidade e do tipo de alimento a ser consumido. De modo indireto, essas variáveis determinam quais produtos agrícolas serão produzidos, exercendo influência, portanto, sobre a disponibilidade de alimentos. Além do mais, a renda costuma ser fortemente correlacionada com a educação, outro importante determinante da segurança alimentar, como bem constataram Costa et al. (2014).

A utilização, terceira dimensão da segurança alimentar, se refere ao modo como os indivíduos consomem os alimentos e ao aproveitamento biológico dos nutrientes. Essa dimensão depende da educação e dos hábitos de consumo, que se associam a fatores culturais, históricos e climáticos (HOFFMANN, 2014; TILMAN; CLARK, 2014; AUESTAD; FULGONI III, 2015; GARNETT, 2016).

Já a última dimensão, a estabilidade alimentar, compreende a manutenção da segurança alimentar ao longo do tempo, o que permite classificar os problemas ligados às três dimensões anteriores em crônicos, sazonais ou transitórios (FAO, 2006; FAO, 2014; LOCKE; HENLEY, 2014). A estabilidade é definida, principalmente, pelos próprios determinantes das dimensões "disponibilidade" e "acesso", importando também o fato de serem permanentes ou transitórios.

O fator regional foi deixado para ser citado por último, não por sua menor importância, muito pelo contrário, mas por ele ser um elemento subjacente

Revista de Economia e Agronegócio - REA | V. 17 | N. 1 | 2019 | pág. 11 
a todas as dimensões da segurança alimentar. Como a produção de cada tipo de alimento e os fluxos de comércio variam de região para região, ese fator afeta a disponibilidade alimentar. Da mesma forma, a renda e a organização do sistema de distribuição alimentar, e consequentemente o acesso, variam entre as regiões. Isso tende a fazer com que os indivíduos consumam maior quantidade de alguns produtos, mais abundantes e baratos em determinada localidade, e menor quantidade de outros. Por fim, o sistema educacional e os hábitos de consumo, influenciados por questões culturais, históricas e climáticas também tendem a variar de região para região (MUSGROVE, 1987; ALONSO, 2017).

Portanto, a partir das diversas fontes citadas nesta seção, é possível elaborar uma representação simplificada das relações entre a segurança alimentar, suas dimensões e seus principais determinantes (Figura 1). Apenas os principais determinantes da segurança alimentar estão representados na Figura 1, e no que se refere a esses, este trabalho se concentra nos efeitos da renda e nos fatores regionais, visando a identificar os segmentos da sociedade.

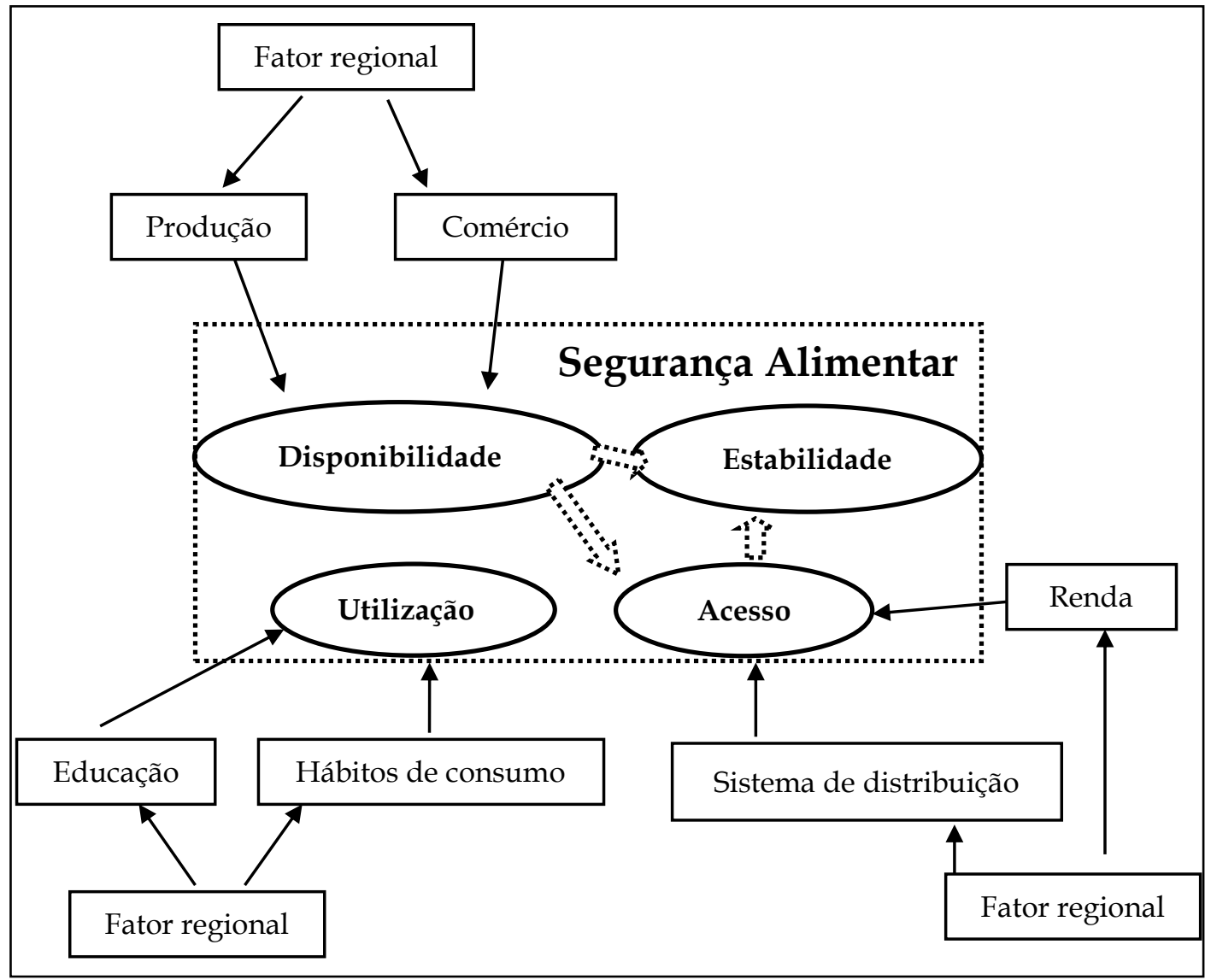

Figura 1. Modelo simplificado representando a segurança alimentar, suas dimensões e seus principais determinantes

Fonte: Elaborado pelos autores. 


\section{PROCEDIMENTOS METODOLÓGICOS}

Neste item, são descritos os dados utilizados e os procedimentos adotados na pesquisa. O primeiro subitem apresenta as fontes de dados e a preparação destes para serem utilizados nas diversas análises. Com o intuito de identificar os grupos de indivíduos em situação de insegurança alimentar, as análises se dividem em duas partes. Na primeira, cujos procedimentos são descritos no segundo e no terceiro subitens, o foco é o alimento adquirido pelos indivíduos - no primeiro caso, segmentados por região geográfica, e no segundo, por estrato de renda. Na segunda parte (quarto subitem), o foco é a situação alimentar, sendo as quantidades de calorias e proteínas adquiridas por indivíduos de diferentes estratos de renda e locais de residência comparadas aos requerimentos nutricionais.

\section{Organização e preparação da base de dados}

A principal base de dados utilizada refere-se ao consumo alimentar dos moradores das capitais dos 26 estados da federação e do Distrito Federal, conforme levantamento feito pela Pesquisa de Orçamentos Familiares (POF) 2008-2009, a mais recente disponível. A POF 2008-2009 investiga o padrão de consumo de bens e serviços dos brasileiros, assim como as características dos domicílios, das famílias ${ }^{2}$ e dos indivíduos que compõem a amostra. Além disso, seu desenho amostral permite expandir as informações da amostra para diferentes níveis geográficos.

Na POF 2008-2009, é possível obter a quantidade e o valor da despesa deflacionado (tendo como base o dia 15 de janeiro de 2009), referentes à aquisição de cada alimento para consumo dentro do domicílio (Caderneta de Despesa - POF 3). A partir desses dados, foi necessário excluir as frações não comestíveis, por meio das Tabelas de Composição de Alimentos (IBGE, 1999), com o intuito de se chegar a estimativas do que poderia vir a ser efetivamente consumido em cada domicílio. Tais quantidades foram depois multiplicadas por suas respectivas composições nutricionais, as quais provieram de três fontes, de acordo com o produto, quais sejam: (i) as Tabelas de Composição Nutricional dos Alimentos Consumidos no Brasil (IBGE, 2011); (ii) a Tabela Brasileira de Composição de Alimentos TACO/UNICAMP; e (iii) a USDA National Nutrient Database for Standard Reference. Esses cálculos resultam nas quantidades totais de nutrientes (quilocalorias de energia e gramas de proteínas) ${ }^{3}$ adquiridas diariamente

2 É importante salientar que o presente trabalho utiliza a família como unidade de referência. Assim como para o IBGE (2010b), o termo família se refere à unidade de consumo, que é composta pelo "conjunto de moradores que compartilham do mesmo estoque de alimentos e/ou realizam um conjunto de despesas alimentares comuns" (IBGE, 2010b).

${ }^{3}$ Uma possível crítica ao uso de calorias e proteínas, em geral, como indicadores de atendimento às necessidades nutricionais, é que muitos produtos são compostos pelas chamadas "calorias vazias", enquanto alimentos proteicos também podem vir acompanhados de elementos nocivos à saúde. Assim, o fato de um indivíduo ter suas $\underline{\text { necessidades atendidas não garante que ele seja saudável. Por outro lado, esse }}$ 
por domicílio. Para algumas análises, conduzidas em nível de indivíduo, a aquisição de nutrientes por domicílio foi dividida pelo número médio de pessoas por domicílio, chegando-se à quantidade total de nutrientes per capita adquiridas diariamente.

\section{Análise do acesso aos alimentos por região geográfica}

Essa análise é feita segmentando os indivíduos por região geográfica e examinando como a renda é despendida em cada uma delas e quais são os grupos de alimentos adquiridos por região. $O$ foco aqui é identificar diferenças de dietas em razão das localidades em que os indivíduos residem.

\section{Análise do acesso aos alimentos por estrato de renda}

Nessa análise, os indivíduos são agrupados em três estratos de renda familiar per capita, quais sejam: (1) até um salário mínimo; (2) de um a três salários mínimos; e (3) acima de três salários mínimos. A partir dessa segmentação, examina-se:

i. Como os indivíduos de cada estrato de renda utilizam suas rendas na aquisição de alimentos, dentro e fora da residência;

ii. Quais grupos de alimentos são mais consumidos por estrato de renda;

iii. Qual é a participação dos grupos de alimentos no suprimento de calorias e proteínas para os indivíduos de cada estrato de renda.

Para realização da análise (iii), assim como para se avaliar a situação alimentar da população (próximo subitem), é necessário calcular o consumo de calorias e proteínas fora de casa. Porém, pelo fato de a POF apresentar apenas o valor despendido na compra de alimentos para consumo fora do domicílio (Despesa Individual - POF4), e não as quantidades adquiridas dessas refeições, optou-se por seguir a metodologia proposta por Moldeto et al. (2013) e já aplicada aos dados da POF por Borlizzi, Delgrossi e Cafiero (2017). Para os estratos de menor renda (estratos 1 e 2), esses autores sugerem que sejam utilizadas, nas estimações das quantidades de calorias e proteínas consumidas fora do domicílio, as mesmas proporções entre despesa e quantidades verificadas para o consumo dentro do domicílio, por localidade e por decil de renda. Ou seja, a proposta é estimar a quantidade média de calorias e proteínas contidas em $\mathrm{R} \$ 1,00$ despendido na aquisição de alimentos para consumo dentro do domicílio, por capital e por decil de renda, e utilizar essa proporção para estimar o consumo de calorias e proteínas consumidas em refeições realizadas fora do domicílio (MOLDETO et al., 2013; BORLIZZI; DELGROSSI; CAFIERO, 2017). 
Contudo, se essa proporção for aplicada aos indivíduos de maior renda (estrato 3), as quantidades de calorias e proteínas tenderão a ser superestimadas, já que esses indivíduos geralmente frequentam restaurantes em que os preços das refeições são mais elevados. Por isso, no caso de estratos de maior renda, Moldeto et al. (2013) e Borlizzi, Delgrossi e Cafiero (2017) sugerem que seja utilizada uma curva de Engel para que as quantidades de calorias e proteínas estimadas estejam mais próximas da aquisição real. Desse modo, foram estimadas as seguintes equações (em que renda é a renda familiar média per capita por dia):

$$
\begin{aligned}
& \ln \text { kcal }=\alpha+\beta \ln \text { renda }+u_{t} \\
& \ln \text { prot }=\alpha+\beta \ln \text { renda }+u_{t}
\end{aligned}
$$

Linearizando, tem-se:

$$
\begin{aligned}
& \text { kcal }=e^{\alpha} * \operatorname{renda}^{\beta}+\vartheta_{\mathrm{t}} \\
& \text { prot }=\mathrm{e}^{\alpha} * \operatorname{renda}^{\beta}+\vartheta_{\mathrm{t}}
\end{aligned}
$$

Os resultados estimados são reportados na Tabela 1 a seguir:

Tabela 1. Coeficientes e estatísticas das curvas de Engel estimadas por grupos de renda

\begin{tabular}{ccc}
\hline & \multicolumn{2}{c}{ Modelos } \\
\cline { 2 - 3 } Variáveis & $\left(1^{\prime}\right)$ & $\left(2^{\prime}\right)$ \\
\hline constante & $4,7641^{* * *}$ & $1,3515^{* * *}$ \\
& $(0,0595)$ & $(0,0550)$ \\
ln renda & $0,6793^{* * *}$ & $0,7089^{* * *}$ \\
$R^{2}$ & $(0,0255)$ & $(0,0247)$ \\
& 0,9632 & 0,9647
\end{tabular}

Legenda: Erros-padrão robustos são apresentados entre parênteses.

***, ${ }^{* *} \mathrm{e}^{*}$ denotam o nível de significância de $1 \%, 5 \%$ e $10 \%$, respectivamente.

A partir dos resultados das estimações, as estimativas das quantidades de calorias e proteínas adquiridas pelos indivíduos do terceiro estrato de renda foram obtidas considerando: $\mathrm{kcal}=117,2 *$ renda $^{0,6793}$ e prot $=3,9 *$ renda $^{0,7089}$.

\section{Avaliação da situação alimentar}

Essa avaliação leva em conta tanto os três estratos de renda quanto cada uma das 26 capitais dos estados da federação e o Distrito Federal. Portanto, a análise que até então estava sendo feita por região passa a sê-lo por unidade federativa. Para cada um desses grupos, as quantidades adquiridas de calorias e proteínas foram comparadas aos requerimentos nutricionais. Tais requerimentos foram definidos de acordo com o sexo, a idade, o tempo de gestação e o fato de a mulher estar ou não amamentando, seguindo as recomendações de Otten et al. (2006). Para cada família, os requerimentos calóricos e proteicos foram estimados a partir da soma das necessidades dos indivíduos que a compõem, com exceção das crianças com idade menor ou igual a 6 meses, que foram excluídas desse cálculo por se considerar que nessa idade a única fonte alimentar deve ser o aleitamento materno. 
Assim, o acesso aos alimentos é analisado a partir das quantidades médias adquiridas para consumo domiciliar per capita, e a situação alimentar é aferida com base no grau de atendimento das necessidades nutricionais da família, somando-se o consumo domiciliar ao consumo fora do domicílio, por capital e para cada estrato de renda, aplicando-se os fatores de expansão (pesos) ajustados pós-estratificação, para se obter estimativas para o universo da pesquisa.

O grau de atendimento das necessidades nutricionais é avaliado por meio de duas variáveis: (i) percentagem de atendimento das necessidades calóricas e proteicas em cada localidade e em cada estrato de renda; e (ii) percentagem de domicílios com acesso a quantidade igual ou superior aos requerimentos calóricos e proteicos, também por localidade e estrato de renda.

\section{ANÁLISE DOS RESULTADOS}

Nesta seção, os resultados obtidos são apresentados e analisados. Conforme indicado no item anterior, a análise inicialmente foca nos alimentos adquiridos pelos grupos de indivíduos segmentados por região geográfica e por estrato de renda (primeiro e segundo subitens), buscando-se identificar o acesso aos alimentos de forma mais agregada. Depois (terceiro subitem), passa-se à análise da situação alimentar, em que se examina o grau de atendimento nutricional dos indivíduos de acordo com o estrato de renda e com a unidade da federação em que residem.

\section{Acesso aos alimentos por região geográfica}

Iniciando pela análise da distribuição e do uso da renda nas regiões do país, notam-se grandes discrepâncias (Tabela 2), sendo os indivíduos residentes nas regiões Sudeste e Sul os que apresentam as maiores rendas familiares per capita médias, as quais ultrapassam o dobro daquelas identificadas na região Norte. Esta última se destaca tanto por ter o menor nível de renda familiar per capita média quanto pelo maior comprometimento da renda com despesas alimentares, principalmente em relação à alimentação consumida dentro do domicílio. Quanto às despesas com alimentação fora do domicílio, há pequenas variações em termos percentuais entre as regiões, o que significa que, em termos absolutos, o gasto é maior nas regiões de maior renda. Em relação ao tipo de despesa, destaca-se o item "Almoço e jantar", particularmente entre os moradores das regiões de maior renda (Tabela 2). Portanto, o uso da renda segue o padrão esperado, em que os moradores das regiões de menor renda absoluta têm que despender maior proporção de recursos com alimentação. 


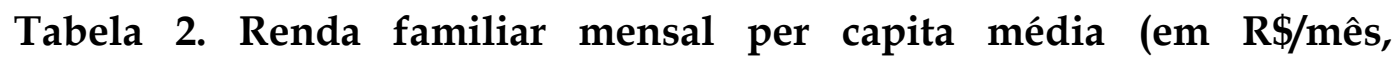
considerando o ano de 2009) e proporção da renda despendida com alimentação dentro e fora do domicílio de acordo com as regiões brasileiras em 2008-2009

\begin{tabular}{lccccc}
\hline & Norte & Nordeste Centro- & Oeste & Sudeste & Sul \\
\hline - $\quad$ Renda per capita (R\$ de 2009/mês) & 912,87 & $1.013,80$ & $1.706,72$ & 1.976 .23 & $1.906,48$ \\
- $\quad \begin{array}{c}\text { Proporção da renda despendida } \\
\text { com alimentação dentro do domicílio }\end{array}$ & $24 \%$ & $19 \%$ & $15 \%$ & $13 \%$ & $13 \%$ \\
$\begin{array}{l}\text { Proporção da renda despendida } \\
\text { com alimentação fora do domicílio }\end{array}$ & $11 \%$ & $9 \%$ & $10 \%$ & $11 \%$ & $10 \%$ \\
$\begin{array}{l}\text { Participação de almoço e jantar nas } \\
\text { despesas fora do domicílio }\end{array}$ & $49 \%$ & $47 \%$ & $60 \%$ & $64 \%$ & $66 \%$ \\
$\begin{array}{l}\text { Participação de outros itens nas } \\
\text { despesas fora do domicílio }\end{array}$ & $51 \%$ & $53 \%$ & $40 \%$ & $36 \%$ & $34 \%$ \\
\hline
\end{tabular}

Fonte: Elaboração própria a partir dos dados da POF 2008-2009 (IBGE, 2010b).

A distribuição dos diversos tipos de alimentos adquiridos para consumo dentro do domicílio mostra diferenças regionais e culturais (Tabela 3). Os indivíduos das capitais da região Norte destacam-se no consumo domiciliar de "carnes, vísceras e pescados", "aves e ovos" e "farinhas, féculas e massas", sendo, porém, os que menos adquirem "frutas", "leite e derivados" e "legumes e verduras". Esse padrão se associa fortemente à dimensão correspondente à disponibilidade, já que as condições climáticas e geográficas da região Norte dificultam a produção de diversas espécies de frutas, verduras e legumes, enquanto favorecem a produção de pescados e carnes. No outro extremo, os indivíduos da região Sul se destacam no consumo de "panificados", " alimentos preparados", "bebidas e infusões" e "leite e derivados", enquanto o Sudeste se destaca na aquisição de "frutas". Já os indivíduos do Centro-Oeste são os que mais adquirem "cereais, leguminosas e oleaginosas", "óleos e gorduras", "sal e condimentos", "açúcares e derivados" e "legumes e verduras".

Por trás dessas distinções regionais, há questões ligadas tanto à disponibilidade, conforme destacado no caso da Região Norte, quanto às diferenças histórico-culturais (dimensão utilização) e de nível e distribuição da renda (dimensão acesso), originando as dietas predominantes em cada localidade. 
Tabela 3. Quantidades médias de alimentos adquiridas per capita (em gramas/dia) para consumo dentro dos domicílios, em 2008-2009, de acordo com as regiões brasileiras

\begin{tabular}{|c|c|c|c|c|c|}
\hline Grupos de Alimentos & Norte & Nordeste & $\begin{array}{c}\text { Centro- } \\
\text { Oeste }\end{array}$ & Sudeste & Sul \\
\hline Cereais, leguminosas e oleaginosas & 101,0 & 87,9 & 129,5 & 80,0 & 65,2 \\
\hline Panificados & 84,1 & 84,7 & 72,0 & 90,8 & 96,5 \\
\hline Óleos e gorduras & 18,2 & 12,5 & 22,0 & 18,4 & 21,4 \\
\hline Bebidas e infusões & 247,3 & 215,9 & 200,0 & 202,6 & 249,7 \\
\hline Enlatados e conservas & 4,0 & 3,1 & 4,1 & 4,9 & 5,6 \\
\hline Sal e condimentos & 15,7 & 14,5 & 25,8 & 20,2 & 19,9 \\
\hline Alimentos preparados & 21,3 & 11,2 & 17,8 & 20,5 & 24,9 \\
\hline Farinhas, féculas e massas & 87,1 & 50,0 & 32,2 & 31,3 & 37,9 \\
\hline Tubérculos e raízes & 18,4 & 29,6 & 39,2 & 39,0 & 40,1 \\
\hline Açúcares e derivados & 55,2 & 50,3 & 59,0 & 48,7 & 50,4 \\
\hline Legumes e verduras & 40,7 & 49,8 & 71,6 & 64,4 & 59,1 \\
\hline Frutas & 79,9 & 104,6 & 146,9 & 148,4 & 138,0 \\
\hline Carnes, vísceras e pescados & 143,4 & 81,8 & 90,9 & 85,9 & 94,2 \\
\hline Aves e ovos & 83,3 & 59,9 & 48,9 & 50,0 & 40,7 \\
\hline Leite e derivados & 70,6 & 99,5 & 161,0 & 170,3 & 230,8 \\
\hline
\end{tabular}

Fonte: Elaboração própria a partir dos dados da POF 2008-2009 (IBGE, 2010b).

\section{Acesso aos alimentos por estrato de renda}

Analisando os indivíduos de acordo com os três estratos de renda discriminados na metodologia, nota-se que os que se encontram nos estratos de menor renda são os que despendem maior proporção de recursos na aquisição de alimentos, majoritariamente para consumo domiciliar (Tabela 4). Por outro lado, parte relevante da despesa com alimentação dos indivíduos de maior renda se refere ao consumo fora do domicílio, principalmente devido à aquisição do item "Almoço e jantar". Note-se que a análise aqui feita com base nos níveis de renda, independente da região, confirma o padrão que havia sido observado no subitem anterior, quando se analisou as diferenças entre regiões.

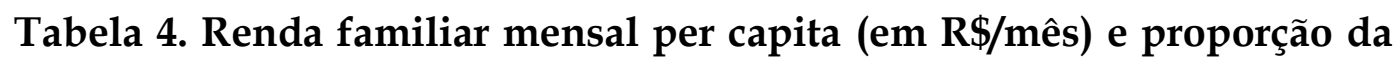
renda despendida com alimentação dentro e fora do domicílio, por estrato de renda familiar per capita, na amostra completa envolvendo todas as capitais do Brasil em 2008-2009

\begin{tabular}{|c|c|c|c|}
\hline & \multicolumn{3}{|c|}{ Estrato de renda familiar per capita } \\
\hline & (1) & (2) & (3) \\
\hline Renda mensal per capita média (em R \$ de 2009) & 254,38 & 746,89 & $3.703,38$ \\
\hline $\begin{array}{l}\text { Proporção da renda despendida com } \\
\text { alimentação dentro do domicílio }\end{array}$ & $30 \%$ & $14 \%$ & $7 \%$ \\
\hline $\begin{array}{l}\text { Proporção da renda despendida com } \\
\text { alimentação fora do domicílio }\end{array}$ & $15 \%$ & $9 \%$ & $9 \%$ \\
\hline Almoço e jantar & $41 \%$ & $53 \%$ & $75 \%$ \\
\hline Outros & $59 \%$ & $47 \%$ & $25 \%$ \\
\hline
\end{tabular}

* Estratos: (1) Até um salário mínimo mensal per capita; (2) De um a três salários mínimos mensais per capita; (3) Acima de três salários mínimos mensais per capita.

Fonte: Elaboração própria a partir dos dados da POF 2008-2009 (IBGE, 2010b). 
Tendo maior acesso a alimentos, os indivíduos de maior renda também têm acesso a maior quantidade de calorias e proteínas, sendo que quase $60 \%$ da ingestão média tanto de calorias quanto de proteínas do estrato de renda 3 provêm do consumo fora do domicílio, enquanto que para o estrato 1 essa proporção cai para aproximadamente $33 \%$ (Tabela 5).

Tabela 5. Quantidades médias de calorias e proteínas (per capita por dia) ingeridas dentro e fora do domicílio, por estrato de renda familiar per capita, na amostra completa envolvendo todas as capitais do Brasil em 2008-2009

\begin{tabular}{lccc}
\hline & \multicolumn{3}{c}{ Estrato de renda familiar per capita* } \\
& $\mathbf{( 1 )}$ & $\mathbf{( 2 )}$ & $\mathbf{( 3 )}$ \\
\hline Calorias (em kcal) & & & \\
$\quad$ Consumidas dentro do domicílio & $1.161,21$ & $1.531,05$ & $2.018,54$ \\
$\quad$ Consumidas fora do domicílio & 567,82 & 987,06 & $2.889,03$ \\
$\quad$ Total & $\mathbf{1 . 7 2 9 , 0 2}$ & $\mathbf{2 . 5 1 8 , 1 1}$ & $\mathbf{4 . 9 0 7 , 5 8}$ \\
Proteínas (em gramas) & 40,20 & 55,12 & 73,71 \\
$\quad$ Consumidas dentro do domicílio & 19,37 & 35,39 & 110,18 \\
$\quad$ Consumidas fora do domicílio & $\mathbf{5 9 , 5 7}$ & $\mathbf{9 0 , 5 1}$ & $\mathbf{1 8 3 , 8 8}$ \\
$\quad$ Total & Estratos: (1) Até um salário mínimo mensal per capita; (2) De um a três salários mínimos \\
mensais per capita; (3) Acima de três salários mínimos mensais per capita. \\
Fonte: Elaboração própria a partir dos dados da POF 2008-2009 (IBGE, 2010b).
\end{tabular}

Quanto às diferenças na composição da dieta alimentar entre os três estratos de renda, nota-se, considerando apenas a aquisição para consumo domiciliar, que os indivíduos dos estratos de renda 1 e 2 têm acesso a quantidades de alimentos inferiores à média nacional (última linha da Tabela 6), sendo que os indivíduos do estrato 1 têm consumo abaixo da média para todos os grupos de alimentos, enquanto que os indivíduos do estrato 2 chegam a consumir quantidades (ligeiramente) acima da média dos itens "cereais, leguminosas e oleaginosas", "óleos e gorduras", "carnes, vísceras e pescados" e "aves e ovos". Por outro lado, os indivíduos pertencentes ao estrato 3 têm acesso a quantidade acima da média para todos os itens, com exceção de "cereais, leguminosas e oleaginosas".

Embora esses resultados se refiram a quantidades de alimentos, e não a nutrientes, é extremamente preocupante que os indivíduos com renda familiar per capita de até um salário mínimo tenham acesso a menos da metade da quantidade adquirida pelos indivíduos com renda superior a três salários mínimos, ainda mais que os indivíduos do estrato 1 são os que mais dependem da alimentação domiciliar para se nutrirem. 
Tabela 6. Quantidades médias de alimentos adquiridas per capita (em gramas/dia) para consumo dentro dos domicílios pelos indivíduos dos diferentes estratos de renda familiar per capita, na amostra completa envolvendo todas as capitais do Brasil em 2008-2009

\begin{tabular}{lcccc}
\hline \multirow{2}{*}{ Grupos de Alimentos } & \multicolumn{3}{c}{ Consumo por estrato de renda familiar (g/dia) } \\
\cline { 2 - 5 } & $\mathbf{( 1 )}$ & $\mathbf{( 2 )}$ & $\mathbf{( 3 )}$ & Média \\
\hline Cereais, leguminosas e oleaginosas & 80,8 & 99,2 & 80,6 & 88,10 \\
Panificados & 65,98 & 78,93 & 114,02 & 87,03 \\
Óleos e gorduras & 13,9 & 18,0 & 20,0 & 17,52 \\
Bebidas e infusões & 114,8 & 187,0 & 328,3 & 214,24 \\
Enlatados e conservas & 1,4 & 3,2 & 8,0 & 4,31 \\
Sal e condimentos & 11,1 & 17,1 & 27,3 & 18,89 \\
Alimentos preparados & 6,4 & 13,2 & 34,0 & 18,25 \\
Farinhas, féculas e massas & 38,9 & 39,6 & 47,6 & 42,05 \\
Tubérculos e raízes & 19,2 & 31,7 & 51,2 & 34,76 \\
Açúcares e derivados & 38,9 & 49,3 & 63,0 & 51,03 \\
Legumes e verduras & 29,4 & 49,0 & 94,4 & 58,71 \\
Frutas & 54,0 & 101,7 & 224,8 & 129,51 \\
Carnes, vísceras e pescados & 66,8 & 92,2 & 110,8 & 91,50 \\
Aves e ovos & 47,0 & 55,9 & 59,5 & 54,69 \\
Leite e derivados & 75,4 & 136,1 & 219,1 & 147,14 \\
\hline Total (g/dia per capita) & $\mathbf{6 6 4 , 0}$ & $\mathbf{9 7 2 , 1}$ & $\mathbf{1 4 8 2 , 5}$ & $\mathbf{1 . 0 5 7 , 7 4}$ \\
\hline Legenda: (1) Até
\end{tabular}

Legenda: (1) Até um salário mínimo mensal per capita; (2) De um a três salários mínimos mensais per capita; (3) Acima de três salários mínimos mensais per capita.

Fonte: Elaboração própria a partir dos dados da POF 2008-2009 (IBGE, 2010b).

A Figura 2 permite que se conheça um pouco mais sobre a participação de cada grupo de alimentos no suprimento de calorias e proteínas. Como os resultados não indicam diferenças expressivas na relevância de cada um deles na provisão de nutrientes em função do estrato de renda, a figura abaixo mostra valores médios.

(a) Calorias

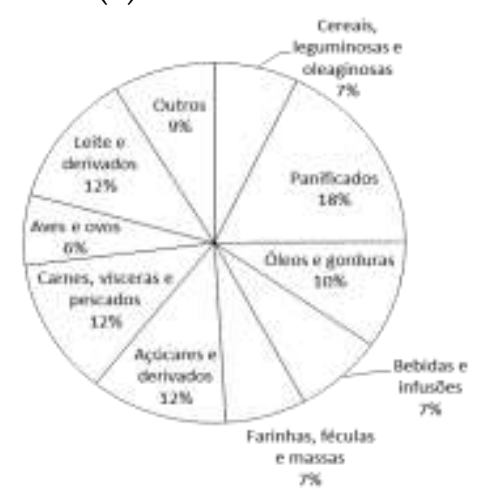

(b) Proteínas

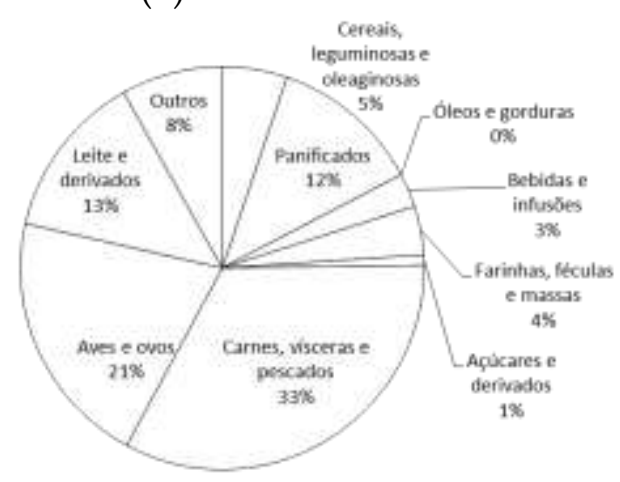

Figura 2. Participação média de cada grupo alimentar na provisão de calorias e proteínas, para consumo dentro do domicílio, em 2008-2009

Nota: na categoria "Outros" estão contidas as proteínas e calorias provenientes do consumo de "enlatados e conservas", "sal e condimentos", "alimentos preparados", "tubérculos e raízes", "legumes e verduras" e "frutas".

Fonte: Elaboração própria a partir dos dados da POF 2008-2009 (IBGE, 2010b). 
Em relação às calorias, cerca de $70 \%$ são provenientes dos seguintes grupos de alimentos: "panificados", "açúcares e derivados", "carnes, vísceras e pescados", "óleos e gorduras", "leite e derivados" e "aves e ovos". Ocorre que somente o consumo de "óleos e gorduras" e de "açúcares e derivados", alimentos tidos como "calorias vazias" por fornecerem apenas energia (TILMAN; CLARKE, 2014), representam cerca de 20\% da ingestão total de calorias. Quanto à provisão de proteínas, os resultados indicam que cerca de $85 \%$ provêm do consumo de cinco grupos de alimentos ("carnes, vísceras e pescados", "aves e ovos", "leite e derivados", "panificados" e "cereais, legumes e oleaginosas"), configurando aproximadamente $67 \%$ das proteínas ingeridas a partir do consumo de alimentos de origem animal (Figura 2).

\section{A situação alimentar}

A análise do grau de atendimento das necessidades nutricionais e do percentual de famílias que tiveram suas necessidades supridas com o acesso a alimentos para consumo dentro e fora do domicílio foi feita tanto de acordo com os estratos de renda familiar per capita quanto de acordo com as capitais do país.

Em relação ao grau de atendimento das necessidades de calorias das famílias com renda familiar per capita de até um salário mínimo (Tabela 7), apenas os indivíduos residentes em Porto Velho e Porto Alegre apresentaram um consumo médio suficiente para satisfazer suas necessidades nutricionais. Em média, os indivíduos desse estrato atingiram o atendimento de $75 \%$ de suas necessidades calóricas, sendo que apenas os de Curitiba apresentaram grau de atendimento menor que 50\%. Apenas $23 \%$ das famílias brasileiras enquadradas nesse estrato de renda tiveram acesso a quantidade suficiente de calorias para satisfazer suas necessidades, sendo que em 14 capitais observa-se um percentual ainda menor, destacando-se Goiânia onde apenas 9\% das famílias do estrato 1 têm acesso a quantidade adequada de calorias.

Em relação aos indivíduos pertencentes aos estratos 2 e 3, nota-se (Tabela 7) que apesar de, em média, haver mais calorias do que o necessário em todas as capitais, para o estrato 3, e em $73 \%$ das capitais, para o estrato 2, há famílias não atendidas de ambos os estratos e em todas as capitais. Ou seja, mesmo no estrato de maior nível de renda, há famílias sem acesso adequado a calorias em todas as capitais do país, a despeito de, em média, haver disponibilidade de mais calorias per capita além do necessário em todas as capitais. No estrato 2, a situação ainda é mais preocupante, pois, apesar de quase três quartos das capitais terem disponibilidade média superior às necessidades, esse excedente mostra-se bastante reduzido, de forma que, em 24 das 26 capitais, menos da metade das famílias tem acesso à quantidade de calorias de que necessitam. 
Tabela 7. Grau de atendimento médio das necessidades de calorias e percentual de famílias com acesso adequado para consumo dentro e fora do domicílio, por estrato de renda familiar per capita, em 2008-2009

\begin{tabular}{|c|c|c|c|c|c|c|}
\hline \multirow[b]{2}{*}{ Capitais \ Estrato de renda } & \multicolumn{3}{|c|}{ Grau de atendimento } & \multicolumn{3}{|c|}{$\begin{array}{l}\text { Percentual de famílias com } \\
\text { acesso adequado }\end{array}$} \\
\hline & (1) & $(2)$ & (3) & (1) & $(2)$ & $(3)$ \\
\hline Porto Velho & $113 \%$ & $122 \%$ & $231 \%$ & $32 \%$ & $35 \%$ & $92 \%$ \\
\hline Rio Branco & $80 \%$ & $150 \%$ & $181 \%$ & $28 \%$ & $55 \%$ & $73 \%$ \\
\hline Manaus & $89 \%$ & $129 \%$ & $229 \%$ & $30 \%$ & $53 \%$ & $93 \%$ \\
\hline Boa Vista & $67 \%$ & $105 \%$ & $194 \%$ & $16 \%$ & $35 \%$ & $81 \%$ \\
\hline Belém & $96 \%$ & $138 \%$ & $220 \%$ & $35 \%$ & $49 \%$ & $96 \%$ \\
\hline Macapá & $86 \%$ & $115 \%$ & $162 \%$ & $30 \%$ & $40 \%$ & $91 \%$ \\
\hline Palmas & $62 \%$ & $79 \%$ & $194 \%$ & $15 \%$ & $30 \%$ & $75 \%$ \\
\hline São Luís & $63 \%$ & $89 \%$ & $169 \%$ & $18 \%$ & $28 \%$ & $91 \%$ \\
\hline Teresina & $76 \%$ & $116 \%$ & $184 \%$ & $19 \%$ & $45 \%$ & $87 \%$ \\
\hline Fortaleza & $73 \%$ & $105 \%$ & $202 \%$ & $27 \%$ & $42 \%$ & $77 \%$ \\
\hline Natal & $82 \%$ & $134 \%$ & $209 \%$ & $27 \%$ & $52 \%$ & $91 \%$ \\
\hline João Pessoa & $60 \%$ & $82 \%$ & $200 \%$ & $17 \%$ & $30 \%$ & $86 \%$ \\
\hline Recife & $71 \%$ & $117 \%$ & $234 \%$ & $23 \%$ & $39 \%$ & $93 \%$ \\
\hline Maceió & $53 \%$ & $76 \%$ & $173 \%$ & $14 \%$ & $26 \%$ & $81 \%$ \\
\hline Aracaju & $77 \%$ & $126 \%$ & $191 \%$ & $27 \%$ & $49 \%$ & $86 \%$ \\
\hline Salvador & $69 \%$ & $106 \%$ & $181 \%$ & $19 \%$ & $38 \%$ & $87 \%$ \\
\hline Belo Horizonte & $64 \%$ & $108 \%$ & $218 \%$ & $16 \%$ & $42 \%$ & $89 \%$ \\
\hline Vitória & $56 \%$ & $116 \%$ & $247 \%$ & $14 \%$ & $35 \%$ & $96 \%$ \\
\hline Rio de Janeiro & $84 \%$ & $97 \%$ & $217 \%$ & $25 \%$ & $38 \%$ & $86 \%$ \\
\hline São Paulo & $76 \%$ & $103 \%$ & $189 \%$ & $24 \%$ & $36 \%$ & $86 \%$ \\
\hline Curitiba & $45 \%$ & $102 \%$ & $215 \%$ & $13 \%$ & $29 \%$ & $90 \%$ \\
\hline Florianópolis & $97 \%$ & $129 \%$ & $243 \%$ & $18 \%$ & $34 \%$ & $98 \%$ \\
\hline Porto Alegre & $102 \%$ & $101 \%$ & $205 \%$ & $28 \%$ & $29 \%$ & $91 \%$ \\
\hline Campo Grande & $61 \%$ & $105 \%$ & $193 \%$ & $20 \%$ & $37 \%$ & $91 \%$ \\
\hline Cuiabá & $69 \%$ & $85 \%$ & $183 \%$ & $15 \%$ & $28 \%$ & $86 \%$ \\
\hline Goiânia & $52 \%$ & $83 \%$ & $203 \%$ & $9 \%$ & $25 \%$ & $83 \%$ \\
\hline Distrito Federal & $74 \%$ & $124 \%$ & $226 \%$ & $26 \%$ & $40 \%$ & $87 \%$ \\
\hline Média & $75 \%$ & $106 \%$ & $205 \%$ & $23 \%$ & $37 \%$ & $88 \%$ \\
\hline
\end{tabular}

Estratos: (1) Até um salário mínimo mensal per capita; (2) De um a três salários mínimos mensais per capita; (3) Acima de três salários mínimos mensais per capita.

Fonte: Elaboração própria, com base nos dados da POF 2008-2009 (IBGE, 2010b) e no trabalho de Otten et al. (2006).

Uma questão aparentemente surpreendente em relação à Tabela 7 é que os indivíduos de menor renda (estrato 1 ) residentes nas capitais mais ricas do país (São Paulo, Rio de Janeiro, Brasília e Belo Horizonte) apresentam graus de atendimento das necessidades calóricas inferiores em relação a algumas outras capitais. Esse fato, que pode ser explicado pelo maior custo de vida nas cidades mais ricas, tem extrema relevância em termos de políticas públicas, uma vez que é comum se associar a questão da desnutrição às regiões mais pobres, o que como se nota, pode não ser o caso.

O panorama em relação à proteína mostrou-se mais favorável (Tabela 8). As necessidades proteicas foram atendidas em quase todas as capitais do país, embora quase metade (pouco menos de 47\%) das famílias tenha acesso inadequado a esse macronutriente. A disponibilidade média de proteína foi superior às necessidades em todas as capitais e para indivíduos de todos os estratos de renda, com exceção daqueles pertencentes ao estrato 1 residentes 
em Curitiba e Vitória. No estrato 2, apesar de, em média, todas as capitais terem disponibilidade per capita de proteína acima dos requerimentos proteicos, cerca de um terço das famílias não tem acesso adequado a esse nutriente, o que não se verifica no estrato 3 em que todas elas têm acesso adequado.

Tabela 8. Grau de atendimento médio das necessidades de proteínas e percentual de famílias com acesso adequado para consumo dentro e fora do domicílio, por estrato de renda familiar per capita, em 2008-2009

\begin{tabular}{|c|c|c|c|c|c|c|}
\hline \multirow[b]{2}{*}{ Capitais \Estrato de renda } & \multicolumn{3}{|c|}{ Grau de atendimento (em \%) } & \multicolumn{3}{|c|}{$\begin{array}{l}\text { Parcela de famílias com } \\
\text { acesso adequado (em } \%)\end{array}$} \\
\hline & (1) & $(2)$ & (3) & (1) & $(2)$ & $(3)$ \\
\hline Porto Velho & 217 & 217 & 407 & 52 & 63 & 100 \\
\hline Rio Branco & 139 & 269 & 333 & 59 & 85 & 100 \\
\hline Manaus & 200 & 287 & 444 & 81 & 87 & 100 \\
\hline Boa Vista & 129 & 198 & 359 & 46 & 67 & 100 \\
\hline Belém & 185 & 285 & 408 & 76 & 86 & 100 \\
\hline Macapá & 183 & 227 & 333 & 66 & 71 & 100 \\
\hline Palmas & 108 & 144 & 390 & 42 & 51 & 100 \\
\hline São Luís & 139 & 176 & 338 & 55 & 63 & 100 \\
\hline Teresina & 151 & 244 & 358 & 60 & 79 & 100 \\
\hline Fortaleza & 128 & 187 & 349 & 54 & 71 & 100 \\
\hline Natal & 142 & 215 & 363 & 56 & 72 & 100 \\
\hline João Pessoa & 105 & 151 & 340 & 36 & 56 & 100 \\
\hline Recife & 114 & 215 & 454 & 44 & 72 & 100 \\
\hline Maceió & 100 & 144 & 331 & 41 & 54 & 100 \\
\hline Aracaju & 149 & 227 & 372 & 55 & 75 & 100 \\
\hline Salvador & 128 & 182 & 349 & 48 & 64 & 100 \\
\hline Belo Horizonte & 126 & 196 & 415 & 46 & 68 & 100 \\
\hline Vitória & 83 & 202 & 471 & 33 & 62 & 100 \\
\hline Rio de Janeiro & 146 & 192 & 415 & 56 & 71 & 100 \\
\hline São Paulo & 134 & 184 & 344 & 52 & 70 & 100 \\
\hline Curitiba & 89 & 166 & 381 & 31 & 53 & 100 \\
\hline Florianópolis & 167 & 239 & 456 & 76 & 58 & 100 \\
\hline Porto Alegre & 212 & 185 & 371 & 51 & 63 & 100 \\
\hline Campo Grande & 109 & 190 & 350 & 47 & 66 & 100 \\
\hline Cuiabá & 123 & 150 & 346 & 41 & 60 & 100 \\
\hline Goiânia & 110 & 154 & 367 & 46 & 54 & 100 \\
\hline Distrito Federal & 132 & 209 & 415 & 51 & 60 & 100 \\
\hline Média & 100 & 128 & 190 & 53 & 68 & 100 \\
\hline
\end{tabular}

Estratos: (1) Até um salário mínimo mensal per capita; (2) De um a três salários mínimos mensais per capita; (3) Acima de três salários mínimos mensais per capita.

Fonte: Elaboração própria, com base nos dados da POF 2008-2009 (IBGE, 2010b) e no trabalho de Otten et al. (2006).

Na verdade, o que mais chama a atenção na Tabela 8 é o consumo excessivo de proteína, particularmente pelos indivíduos do estrato 3. Considerando que, segundo dados da Organização para Cooperação e Desenvolvimento Econômico (OCDE) ${ }^{4}$, o Brasil é o $6^{\circ}$ maior consumidor de carne do mundo, com consumo per capita de 78,6 kg em 2017, e que esse consumo deva estar

${ }^{4}$ https:// data.oecd.org/agroutput/meat-consumption.htm 
mais concentrado entre os indivíduos de maior renda, justifica-se a situação de obtenção excessiva de proteína (em muitos casos, até quatro vezes maior que as necessidades) no estrato de maior renda em todas as capitais do país.

Os resultados reportados nas tabelas 7 e 8 confirmam, portanto, a influência da renda sobre o acesso alimentar, visto que ambos, o grau de atendimento médio das necessidades nutricionais e a proporção de famílias que têm suas necessidades atendidas adequadamente, aumentam conforme aumenta a renda familiar per capita.

Em algumas localidades, a influência da renda é ainda mais relevante. Entre os indivíduos situados nos estratos de renda extremos, a maior disparidade do grau de atendimento das necessidades calóricas (Tabela 7) foi observada em Curitiba, sendo o grau médio dos indivíduos com renda familiar per capita acima de três salários mínimos 4,78 vezes superior ao grau médio de atendimento daqueles de menor renda. Ademais, nessa capital, os indivíduos pertencentes ao segundo estrato de renda apresentam o dobro do grau de atendimento das necessidades daqueles do primeiro estrato de renda, a mesma diferença observada entre os residentes em Vitória.

Em relação à Curitiba, é notável que, tanto em termos de calorias quanto de proteínas, o grau de atendimento dos indivíduos de menor renda é muito aquém do esperado. Com efeito, a renda média per capita dos indivíduos residentes em Curitiba que fazem parte do estágio 1 é, de acordo com os dados deste trabalho, a sexta maior do país, enquanto os gastos com alimentação desses indivíduos ocupam a antepenúltima posição entre todas as capitais. Uma possível explicação para os reduzidos gastos com alimentação é que os membros do estágio 1 que residem em Curitiba podem estar despendendo muito mais com outras despesas básicas importantes, tal como moradia (aluguel, conta de água, luz etc.), do que os indivíduos do mesmo estrato que residem em outras capitais. Contudo, para identificar se essa justificativa é plausível, seria necessário examinar as demais despesas domiciliares, o que vai além do escopo deste trabalho.

Os resultados também refletem a desigualdade de acesso a alimentos entre os indivíduos do mesmo estrato de renda, o que indica que há outros elementos, além da renda, tais como o custo de vida local, hábitos culturais e grau de conhecimento sobre alimentação, que afetam o consumo de alimentos. Para identificar esse tipo de variação, foi importante não ter se avaliado a situação alimentar somente pelo grau médio de atendimento das necessidades, visto que há muitas capitais em que o grau médio é adequado, mas há um percentual elevado de famílias com acesso inadequado, mesmo no caso de famílias de nível de renda mais elevado. Essa disparidade entre o grau médio de atendimento e a quantidade de famílias com acesso adequado a calorias e proteínas implica a existência de indivíduos consumindo em excesso em detrimento de outros.

\section{CONCLUSÕES E IMPLICAÇÕES}

Esta pesquisa confirma a importância da renda para o acesso aos alimentos, hipótese já consagrada na literatura, ao demonstrar que os indivíduos de 
maior renda obtêm maior grau de atendimento de suas necessidades, usando menor parcela de suas rendas. Por outro lado, os indivíduos de menor renda são os que estão mais sujeitos à insegurança alimentar.

Além disso, a metodologia adotada neste trabalho permitiu a obtenção de conhecimentos importantes para uma melhor compreensão da situação de desnutrição no Brasil. Em primeiro lugar, o uso da ingestão de proteína como um dos indicadores mostrou não haver carência desse nutriente no país. O fator crítico em termos de segurança alimentar no Brasil é a ingestão de calorias, o que reforça a pertinência de outros trabalhos que utilizaram a ingestão de calorias como indicador único de insegurança alimentar. Em segundo lugar, o fato de se medir, além do grau médio de atendimento nutricional, a percentagem de domicílios cujos moradores têm suas necessidades atendidas, mostrou que o grau médio de atendimento de um grupo é, em muitos casos, enganoso, já que as desigualdades muitas vezes fazem com que haja desnutrição numa quantidade considerável de domicílios apesar de, na média, todos estarem sendo atendidos. Por fim, a segmentação da análise, incluindo as dimensões renda e região (estado federativo), mostrou que a desnutrição está disseminada pelo país, afetando até mesmo as localidades de maior nível de renda, embora atinja especialmente os mais pobres.

A aparente contradição entre os resultados aqui obtidos e os de outros estudos, tal como o de Aguiar e Costa (2017), que concluíram não haver carência nutricional, examinando a disponibilidade alimentar per capita, se deve a diferenças entre os procedimentos adotados. A disponibilidade alimentar, dada pela produção somada às importações menos as exportações, não leva em conta a desigualdade na distribuição dos alimentos (diferenças de acesso) nem as expressivas perdas que ocorrem ao longo da cadeia produtiva, o que faz com que a quantidade de alimentos efetivamente disponível para consumo seja bastante inferior à disponibilidade estimada. O fato de que grande quantidade de alimentos se deteriora e deixa de ser consumida, o que não é um problema exclusivo do Brasil, soma-se à desigualdade na distribuição entre as famílias, agravando a questão da desnutrição no país.

Ademais, a importância da renda no grau de desnutrição, identificada neste estudo, indica que essa variável econômica deve ser o foco das políticas públicas que visem a promover a segurança alimentar. Nesse contexto, poder-se-ia incluir políticas de transferência de renda, como o "Bolsa Família", assim como aquelas que barateassem os alimentos, tais como o crédito subsidiado à produção de alimentos e as isenções fiscais de produtos alimentares.

Por fim, o estudo mostrou que o problema da desnutrição pode ser mais sério e abrangente do que se supunha, sendo necessárias ações para melhorar o estado nutricional dos brasileiros, visto ser essa melhoria condição sine qua non para o desenvolvimento do país. Novos estudos poderiam agregar mais informações sobre o grau e as causas da desnutrição no Brasil, explorando mais a questão das perdas de alimentos, incluindo mais alimentos nos cálculos da ingestão de calorias e proteínas pelos 
indivíduos, computando outras formas de nutrientes (tais como os micronutrientes) e avaliando as ações que vêm sendo feitas no Brasil e no exterior para combater a fome e a desnutrição.

\section{REFERÊNCIAS}

AGUIAR, D.R.D. A situação nutricional no Brasil. OIKOS - Revista Brasileira de Economia Doméstica, Viçosa, MG, 1(11): 67-90, 1998.

AGUIAR, D.R.D.; COSTA, G.N. The impacts of the food-feed-fuel competition on Brazilian food supply. Revista de Economia e Agronegócio, 15(2): 163-182, 2017.

ALONSO, E.B.; COCKX, L.; SWINNEN, J. Culture and food security. LICOS - Centre for Institutions and Economic Performance, KU Leuven. Discussion Paper 398/2017. August, 2017. Disponível em: <https://feb.kuleuven.be/drc/licos/publications/dp/dp-398>. Acesso em: 18 maio 2019.

AUESTAD, N.; FULGONI III, V. L. What current literature tell us about sustainable diets: emerging research linking dietary patterns, environmental sustainability, and economics. Advances in Nutrition, 6(1):1936, 2015. DOI: 10.3945/an.114.005694.

BORLIZZI, A.; DELGROSSI, M. E.; CAFIERO, C. National food security assessment through the analysis of food consumption data from Household Consumption and Expenditure Surveys: The case of Brazil's Pesquisa de Orçamento Familiares 2008/09. Food Policy, 72: 20-26, 2017. DOI: 10.1016/j.foodpol.2017.08.009.

COELHO, A. B. A demanda de alimentos no Brasil, 2002/2003. 2006. 250 p. Tese (Doutorado em Economia Aplicada) - Universidade Federal de Viçosa, Viçosa. Disponível em: <http://livros01.livrosgratis.com.br/cp053563.pdf> . Acesso em: 17 maio 2019.

FURTUOSO, M. C. O. Redistribuição de e consumo de Alimentos no Estado de São Paulo. 1981. 106 p. Dissertação (Mestrado em Economia Agrária) - Escola Superior de Agricultura Luiz de Queiroz, Universidade de São Paulo, Piracicaba.

COSTA, L.V.; SILVA, M.M.C.; BRAGA, M.J.; LÍRIO, V.S. Fatores associados à segurança alimentar nos domicílios brasileiros em 2009. Economia e Sociedade, Campinas, 23(2): 373-394, 2014.

FOOD AND AGRICULTURE ORGANIZATION - FAO. Food Security. Policy Brief, issue 2, Rome, 2006. 
FAO, IFAD, UNICEF, WFP and WHO. The state of food security and nutrition in the world 2018 - building climate resilience for food security and nutrition. Rome, FAO, 2018. Licence: CC BY-NC-SA 3.0 IGO.

FRISON, E.; CHERFAS, J.; HODGKIN, T. Agricultural Biodiversity Is Essential for a Sustainable Improvement in Food and Nutrition Security. Sustainability, 3:238-253, 2011. DOI: 10.3390/su3010238

GARNETT, T. Planting up solutions: can eating patterns be both healthier and more sustainable? Science, 353(6305):1202-1204, 2016. DOI: 10.1126/science.aah4765

GROSS, R.; SCHOENEBERGER, H.; PREUSS, H.J.A. The four dimensions of food and nutritional security: definitions and concepts. FAO,Roma, 2000. Disponível em: <http://www.fao.org/elearning/course/fa/en/pdf/p01_rg_concept.pdf>. Acesso em: maio 2019.

HOFFMANN, R. Brasil, 2013: mais segurança alimentar. Segurança Alimentar e Nutricional, Campinas, 21(2): 422-436, 2014.

HLPE. Nutrition and food systems. A report by the High Level Panel of Experts on Food Security and Nutrition of the Committee on World Food Security, Rome, 2017.

INSTITUTO BRASILEIRO DE GEOGRAFIA E ESTATÍSTICA - IBGE. Tabelas de composição de alimentos: Estudo Nacional da Despesa Familiar. $5^{\mathrm{a}} \mathrm{ed}$. Rio de Janeiro, 1999, 137 p. Disponível em: <https:/ / biblioteca.ibge.gov.br/visualizacao/monografias/GEBIS\%20\%20RJ/endef/1999_Tabela\%20de\%20composicao\%20de\%20alimentos.pdf >. Acesso em: ago. 2017.

INSTITUTO BRASILEIRO DE GEOGRAFIA E ESTATÍSTICA - IBGE. Pesquisa Nacional por Amostra de Domicílios. Segurança Alimentar 2004/2009. Ministério do Planejamento, Orçamento e Gestão. Instituto Brasileiro de Geografia e Estatística - IBGE. Diretoria de Pesquisas. Coordenação de Trabalho e Rendimento. 2010a.

INSTITUTO BRASILEIRO DE GEOGRAFIA E ESTATÍSTICA - IBGE. Pesquisa de Orçamentos Familiares 2008-2009 - Microdados. IBGE, 2010b. Disponível em:

<http://www.ibge.gov.br/home/estatistica/populacao/condicaodevida Lpof/2008_2009/microdados.shtm>. Acesso em: abr. 2016.

INSTITUTO BRASILEIRO DE GEOGRAFIA E ESTATÍSTICA - IBGE. Pesquisa de Orçamentos Familiares 2008-2009. Tabelas de Composição Nutricional dos Alimentos Consumidos no Brasil. Ministério do Planejamento, Orçamento e Gestão. Instituto Brasileiro de Geografia e Estatística - IBGE. Diretoria de Pesquisas. Coordenação de Trabalho e Rendimento. 2011. 
INSTITUTO BRASILEIRO DE GEOGRAFIA E ESTATÍSTICA - IBGE. Pesquisa Nacional por Amostra de Domicílios. Segurança Alimentar 2013. Ministério do Planejamento, Orçamento e Gestão. Instituto Brasileiro de Geografia e Estatística - IBGE. Diretoria de Pesquisas. Coordenação de Trabalho e Rendimento. 2014.

LOCKE, A.; HENLEY, G. A review of the literature on biofuels and food security at a local level: assessing the state of the evidence. ODI, Londres, 2014. Disponível em: <http:/ / www.indiaenvironmentportal.org.in/files/file/A\%20review\%20 of $\% 20$ the $\% 20$ literature $\% 20$ on \%20biofuels.pdf >. Acesso em: abr. 2016.

MAXWELL, S.; FRANKENBERG, T. Household food security: concepts, indicators, measurements - a technical review. UNICEF, IFAD. New York/Roma, 1992.

MOLDETO, A.; TROUBAT, N.; LOKSHIN, M.; SAJAIA, Z. Analyzing food security using household survey data: streamlined analysis with ADePT software. World Bank, Washington DC, 2013. Disponível em : <https://openknowledge.worldbank.org/handle/10986/18091>. Acesso em: 28 dez. 2017.

MUSGROVE, P. Os fatores econômicos no comportamento nutricional dos consumidores. Caderno NESP, Brasília, 1(1): 9-32, 1987.

NÚCLEO DE ESTUDOS E PESQUISAS EM ALIMENTAÇÃO NEPA/UNICAMP. Tabela Brasileira de Composição de Alimentos - TACO. Campinas: Universidade Estadual de Campinas, Núcleo de Estudos e Pesquisas em Alimentação, $4^{\mathrm{a}}$ ed, 2011, 161 p. Disponível em: <https://www.unicamp.br/nepa/taco/contar/

taco_4_edicao_ampliada_e_revisada> Acesso em: ago. 2017.

OTTEN, J.J.; HELLWIG, J.P.; MEYERS, L. (Ed.). Dietary reference intakes: the essential guide to nutrients requirements. Washington, DC: The Nacional Academies Press, 2006.

PEREDA, P.C.; ALBES, D.C.O. Qualidade alimentar dos brasileiros: teoria e evidência usando demanda por nutrientes. Pesquisa e Planejamento Econômico, 42(2): 239-260, 2012.

RODRIGUES, C.T.; COELHO, A.B.; BRAGA, M.J.; GOMES, A.P. Demanda por nutrientes nas principais regiões metropolitanas do Brasil no período de 1995-2003. Economia Aplicada, 16(1): 5-30, 2012.

SEN, A.K. Poverty and famines: an essay on entitlement and deprivation. Oxford: Clarendon Press, 1981. 257 p.

TILMAN, D.; CLARK, M.; Global diets link environmental sustainability and human health. Nature, 515: 518-532, 2014. 
UNITED STATES. Department of Agriculture. Agricultural Research Service. USDA National Nutrient Database for Standard Reference: release SR28. Beltsville, 2015. Disponível em: <https://ndb.nal.usda.gov/ndb/>. Acesso em: ago. 2017.

VON GREBMER, K.; BERNSTEIN, J.; BROWN, T.; PRASAI, N.; YOHANNES, Y. 2017 Global Hunger Index: The inequalities of hunger. Washington, DC: IFPRI; Bonn: Welthungerhilfe; Dublin: Concern Worldwide; 2017, 50 p.

WEINGÄRTNER, L. The concept of food and nutrition security. International Training Course "Food and Nutrition Security Assessment Instruments and Intervention Strategies". Background Paper No. 1. German Agency for Technical Cooperation. August, 2004. Disponível em: <http://www.oda-alc.org/documentos/1341934899.pdf>. Acesso em: 18 mar. 2019.

WORLD BANK. Poverty and hunger: issues and options for food security in developing countries. Washington DC, 1986.

WORLD FOOD SUMMIT. Rome Declaration on World Food Security and World Food Summit Plan of Action. Rome, 1996. 